\title{
Elasticidades dos rendimentos do trabalho em relação ao salário mínimo: a experiência de um período recente de crescimento do salário mínimo ${ }^{1}$
}

\author{
João Saboia ${ }^{2}$
}

\section{Resumo}

Na última década, o salário mínimo (SM) passou por um período de forte crescimento, ao mesmo tempo em que a remuneração média do trabalho sofreu queda. Esse resultado, aparentemente incoerente, motivou este artigo sobre a evolução dos rendimentos do trabalho no período 1995/2006 e o cálculo das elasticidades de tais rendimentos em relação ao SM. Foi verificado que o SM manteve sua representatividade como referência mínima legal no período, sem que houvesse queda da parcela de pessoas ocupadas recebendo $1 \mathrm{SM}$. Apesar disso, houve aumento do percentual de trabalhadores abaixo do SM, usualmente pertencentes ao setor informal da economia. Ao desagregar os trabalhadores segundo sua posição na ocupação, notou-se que as elasticidades são sistematicamente mais elevadas para os valores de rendimentos no entorno do valor do SM, tanto acima quanto abaixo. Portanto, o aumento do SM foi transferido, mesmo que parcialmente, para faixa importante da população ocupada de baixos rendimentos. Entretanto, na medida em que nos afastamos do valor do SM, as elasticidades se reduzem, muitas vezes tornando-se negativas nas duas extremidades dos rendimentos. Os resultados do artigo corroboram, para o período recente de forte crescimento do SM, resultados encontrados por outros autores em períodos anteriores, reforçando a importância do papel do SM para a melhoria da distribuição dos rendimentos do trabalho.

Palavras-chave: Salário mínimo; Salários; Rendimentos do trabalho; Distribuição de renda; Elasticidades-renda.

\begin{abstract}
Elasticities of labor income in relation to minimum wage in Brazil: The experience in a period of high increase of minimum wage

In the last decade minimum wage showed a high growth while average labor income suffered a fall. This apparently incoherent result motivated this article on the evolution of labor income in $1995 / 2006$ and the estimation of the elasticities of labor income in relation to minimum wage. It was verified that minimum wage kept its representation as legal minimum reference in the period. There was no fall in the percentage of workers receiving exactly one minimum wage. However it was verified an increase in the percentage of workers from the informal sector below its level. When
\end{abstract}

(1) Trabalho recebido em outubro de 2008 e aprovado em março de 2009. Este artigo contou com o apoio do CNPq. O autor agradece a Bernardo Nunes, Luana Rufino e Vitor Valle pelo trabalho de processamento dos dados. Agradece também as sugestões de um parecerista anônimo.

(2) Professor titular e atual diretor do Instituto de Economia da Universidade Federal do Rio de Janeiro (IE/UFRJ), Rio de Janeiro, RJ, Brasil. E-mail: $\underline{\text { saboia@ ie.ufrj.br. }}$ 
João Saboia

disaggregating workers according to its occupation position, it was noticed that the elasticities are systematically higher for income levels around the value of the minimum wage. Therefore, the increase of minimum wage had a strong influence for many workers of low income. However, when moving away (up and down) from the value of minimum wage, the elasticities decrease, being usual to become negative when considered the two extremities of the labor income distribution. The findings of this article for the recent period of high growth of minimum wage corroborate results found by other authors in previous periods, strengthening the importance of the role of minimum wage for the improvement of the labor income distribution.

Key words: Minimum wage; Wages; Labor revenue; Income distribution; Income elasticities. JEL J31, O15, O17.

\section{Introdução}

Desde meados dos anos 1990, o salário mínimo (SM) tem passado por um processo de recuperação com importantes consequências sobre a distribuição dos rendimentos do trabalho. Seu papel não se limita apenas aos rendimentos do trabalho na medida em que também nas aposentadorias e pensões oficiais o piso utilizado é o próprio SM. Até mesmo a assistência social utiliza o SM como valor de referência em programas como o Benefício de Prestação Continuada (BPC). Portanto, o papel do SM não está restrito aos rendimentos gerados no mercado de trabalho.

Embora sem regras definidas para os reajustes, a conjuntura política do passado recente favoreceu o aumento do SM após a implantação do Plano Real e a redução do processo inflacionário. As informações atualmente disponíveis apontam para a continuidade do processo de crescimento do SM no futuro, embora, provavelmente, numa intensidade menor que na última década.

Ao mesmo tempo em que o SM crescia, os rendimentos médios do trabalho apresentavam queda, iniciada na segunda metade da década de 1990 e só revertida a partir de 2005. Tal fato, até certo ponto surpreendente, levanta dúvidas sobre o potencial que o SM teria tido no sentido de efetivamente influenciar os níveis salariais dos trabalhadores com menores níveis de remuneração. Como compatibilizar um SM crescente com rendimentos médios do trabalho em queda?

Vários autores têm discutido nos últimos anos o papel do SM na determinação dos rendimentos do trabalho no país. Em geral, há concordância sobre a importância do SM sobre os salários em uma faixa de rendimentos próximos de seu valor. A maior discordância é sobre a intensidade do efeito. ${ }^{3}$

(3) Entre os trabalhos recentes sobre o tema podem ser mencionados, por exemplo, Fajnzylber (2001), Foguel; Ramos e Carneiro (2001), Lemos (2001 e 2005), Ulyssea e Foguel (2006) e Soares (2006). 
$\mathrm{Na}$ medida em que o SM influencia os rendimentos do trabalho e os rendimentos de vários tipos de transferências de renda, seu potencial como elemento de redistribuição dos rendimentos é considerável. Na discussão sobre o papel do SM na melhoria da distribuição de renda em geral, e não apenas do trabalho, há posições divergentes. Alguns minimizam seus efeitos, enquanto outros reconhecem no SM um elemento importante de melhoria da distribuição de renda. $^{4}$

O principal objetivo deste artigo é discutir o papel do SM na distribuição dos rendimentos do trabalho no país a partir da experiência pós-Plano Real. Defende-se que o SM teve um papel importante na determinação dos níveis de renda para aqueles que recebem valores próximos do SM, especialmente no setor formal da economia. $\mathrm{O}$ argumento é também o de que, embora tenha aumentado a parcela de pessoas ocupadas recebendo menos de $1 \mathrm{SM}$, mesmo aqueles que "ficaram um pouco para trás" foram, de alguma forma, beneficiados pelo crescimento do SM real, que teria sido transferido parcialmente para níveis mais baixos de remuneração. Isso ocorreu também para níveis um pouco superiores ao valor do SM. Portanto, o SM teria funcionado como uma espécie de "farol" para os níveis relativamente baixos de rendimento do trabalho, cuja luz vai se apagando na medida em que se afasta para baixo e para cima de seu valor. Assim, para os níveis extremamente baixos de rendimentos encontrados no setor informal, a influência do SM é muito pequena. Da mesma forma, seu efeito sobre os altos rendimentos tem sido nulo, quando não negativo.

A metodologia utilizada no artigo se baseia no cálculo das elasticidades das remunerações do trabalho principal em relação ao SM no período 1995/2006 e em alguns subperíodos, diferenciando a situação dos empregados e trabalhadores domésticos com e sem carteira assinada. É analisada também a situação da remuneração dos trabalhadores por conta própria. Como são utilizados os dados da Pesquisa Nacional por Amostra de Domicílios (PNAD), são acompanhados os rendimentos de algumas faixas da distribuição, basicamente décimos e vigésimos, em vez dos rendimentos de cada indivíduo, o que só seria permitido com o uso da Pesquisa Mensal de Emprego (PME).

O uso de elasticidades dos rendimentos do trabalho em relação ao SM já foi feito em outros artigos sobre o tema, como em Fajnzylber (2001), Lemos (2001) e Soares (2002) utilizando dados da PNAD ou da PME. A principal contribuição deste trabalho é o uso de dados mais recentes, quando o crescimento

(4) Para uma visão geral das diversas posições, ver, por exemplo, Barros; Corseuil e Cury (2000), Neri; Gonzaga e Camargo (2001), Corseuil e Servo (2002), Baltar; Dedecca e Krein (2005), Soares (2006), Giambiagi e Franco (2007) e Saboia (2007). 
João Saboia

do SM se acelerou, confirmando a importância do SM na determinação dos rendimentos nas faixas próximas ao valor do SM e diferenciando a situação dos trabalhadores nas diferentes posições na ocupação típicas dos segmentos formal e informal da economia.

Na próxima seção é apresentada a evolução do salário mínimo e das remunerações dos trabalhadores referidas ao SM no período em estudo. Na seção seguinte é desenvolvido o cálculo das elasticidades e diferenciada a situação dos vários grupos de trabalhadores considerados. Finalmente, são apresentadas as principais conclusões do trabalho. Há ainda um Anexo Estatístico com o cálculo das elasticidades e da variação real dos rendimentos do trabalho principal por décimos para os períodos 1995/2006 e 2002/2006.

Os resultados do estudo são importantes no sentido de reforçar o papel do SM na determinação dos salários mais baixos, mostrando seu potencial e suas limitações para a melhoria do processo de distribuição de renda no país.

\section{0 salário mínimo e sua importância na distribuição salarial}

Criado em 1938 e implantado em 1940, o salário mínimo já possui uma longa história de quase 70 anos no Brasil. Após sofrer forte queda em seu poder aquisitivo ao longo dos anos 1940, o SM foi beneficiado por dois reajustes generosos concedidos por Vargas na primeira metade dos anos 1950. O presidente Kubitschek manteve uma política liberal para o SM, de modo que foi durante seu governo que ele atingiu os maiores níveis reais de todos os tempos.

Com a aceleração do processo inflacionário na virada para os anos 1960, o SM sofreu fortes quedas, acentuadas pela política salarial do novo governo militar. A queda posterior da inflação, entretanto, beneficiou o SM, mantendo-o em nível relativamente constante da segunda metade dos anos 1960 até o final da década de 1970, quando a inflação voltou a subir.

Ao longo dos anos 1980 e primeira metade dos anos 1990, o SM passou por fortes flutuações, acumulando perdas provocadas pela aceleração inflacionária, que culminaram com a hiperinflação do início dos anos 1990.

Com o Plano Real e o controle da inflação que se seguiu, o SM iniciou um período de recuperação, sem paralelo com a experiência dos anos anteriores. Desde 1994, o SM quase dobrou em termos reais, sendo beneficiado especialmente nos anos de 1995, 2001 e a partir de 2004, quando houve uma política explícita de valorização do SM no governo Lula (Gráfico 1). 
Elasticidades dos rendimentos do trabalho em relação ao salário mínimo: a experiência de um período recente ...

Gráfico 1

Salário mínimo real - 1944/2007 (em R\$ de 2007)

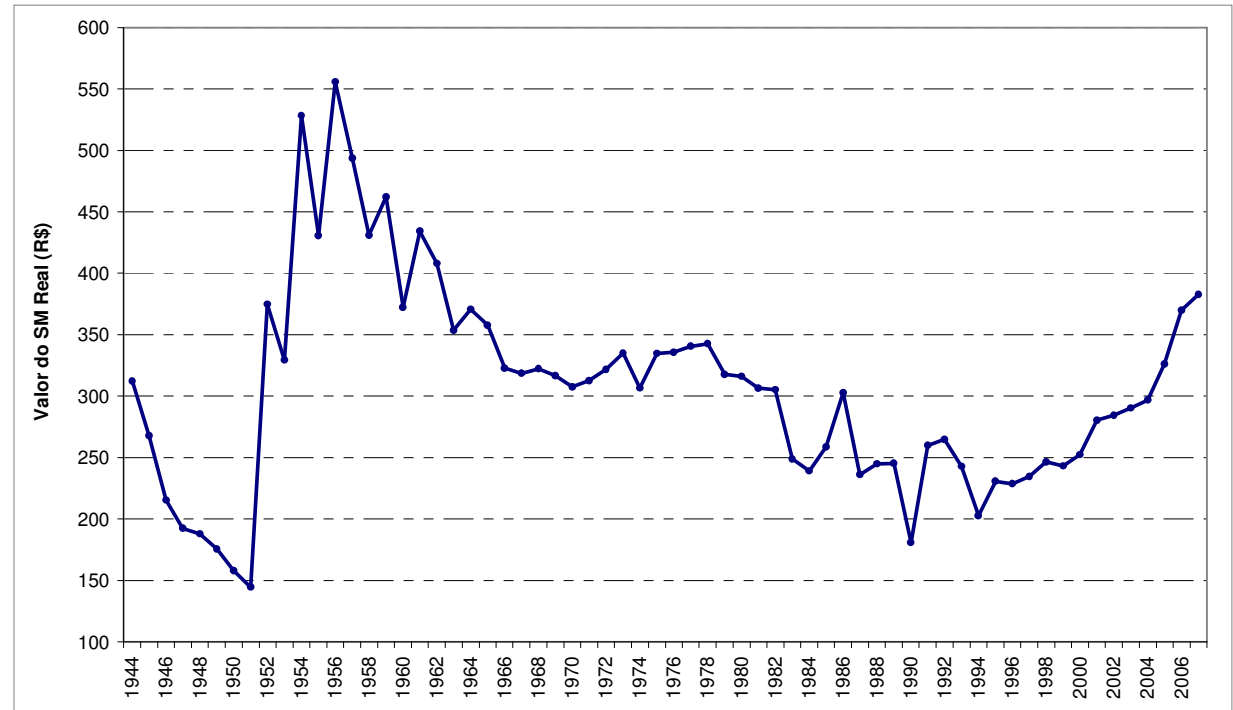

Fonte: IPEADATA.

O forte crescimento do SM na última década poderia levantar dúvidas sobre sua efetiva capacidade de ser aceito pelo mercado de trabalho e repassado aos trabalhadores. Em outras palavras, até que ponto sua importância teria se mantido nos últimos anos? Estaria diminuindo o número de pessoas que recebem exatamente $1 \mathrm{SM}$ e aumentando aquelas abaixo do SM?

Será estudado o período 1995/2006, quando o SM cresceu 63\% em termos reais. ${ }^{5}$ Cabe lembrar que se trata de um período em que os rendimentos médios do trabalho sofreram fortes quedas após os primeiros efeitos do Plano Real, que só começaram a ser revertidas em 2005. Será considerada a remuneração da população ocupada no trabalho principal, desagregando-se em cinco posições na ocupação - empregados com carteira assinada; empregados sem carteira assinada; trabalhadores domésticos com carteira assinada; trabalhadores domésticos sem carteira assinada; e trabalhadores por conta própria. Tais grupos representam pouco menos de $80 \%$ da população ocupada no país no período. Curiosamente, apesar do crescimento do SM, o emprego com carteira assinada, inclusive para

(5) Toma-se como referência o valor do SM no mês de setembro, quando são feitos os levantamentos da PNAD. Optou-se por excluir 1994 do estudo devido às altas taxas de inflação ainda presentes em grande parte do ano. 
trabalhadores domésticos, pagando, portanto, ao menos 1 SM, cresceu proporcionalmente entre 1995 e $2006^{6}$ (Tabela 1).

Tabela 1

Distribuição das pessoas ocupadas por posição na ocupação - 1995/2006

\begin{tabular}{l|r|r|r|c}
\hline \multicolumn{1}{c|}{ Posição na Ocupação } & \multicolumn{1}{c|}{1995} & $\%$ & \multicolumn{1}{c}{2006} & $\%$ \\
\hline Empregados com carteira & 19.664 .844 & 28,2 & 28.216 .051 & 32,2 \\
\hline Outros empregados sem carteira & 11.368 .189 & 16,3 & 15.534 .966 & 17,7 \\
\hline Domésticos com carteira & 980.736 & 1,4 & 1.832 .256 & 2,1 \\
\hline Domésticos sem carteira & 4.151 .353 & 6,0 & 4.882 .459 & 5,6 \\
\hline Conta própria & 15.719 .098 & 22,6 & 18.423 .047 & 21,0 \\
\hline Subtotal & 51.884 .220 & 74,5 & 68.888 .779 & 78,6 \\
\hline Outras & 17.744 .388 & 25,5 & 18.745 .806 & 21,4 \\
\hline Total & 69.628 .608 & 100 & 87.634 .585 & 100 \\
\hline
\end{tabular}

Fonte: PNAD.

Antes de continuar a discussão, é preciso fazer uma observação sobre os dados da PNAD. Nota-se que, ao informarem os rendimentos, os entrevistados têm a tendência de arredondar os dados. Assim, números terminados em dois ou mais zeros (100, 200, 300 etc.) são mais prováveis de serem informados do que 90, 110, 190, 210, 290, 310 etc. Esse fato é importante, pois o SM valia R\$ 100 em 1995, R\$ 200 em 2002 e R\$ 300 em 2005, porém R\$ 180 em 2001 e R\$ 350 em 2006. Assim, o indivíduo ao informar um rendimento de R\$ 300 em 2005 pode estar informando $1 \mathrm{SM}$ ou simplesmente estar arredondando o valor de seu rendimento próximo desse valor, enquanto ao dizer que recebia $\mathrm{R} \$ 180 \mathrm{em} 2001$ certamente está dizendo que recebia $1 \mathrm{SM}$ naquele ano. Dessa forma, as comparações ao longo do tempo devem ser feitas com as devidas ressalvas de informação. Esse é um problema existente em qualquer levantamento similar à PNAD, mas que se torna mais importante na medida em que se deseja acompanhar o valor exato de $1 \mathrm{SM}$ ao longo do tempo.

O Gráfico 2 ilustra as informações de rendimento do trabalho principal levantadas pela PNAD para o ano de 2006, quando o SM valia R\$350. Conforme pode ser verificado, além do próprio valor do $\mathrm{SM}$, os rendimentos mais informados foram $\mathrm{R} \$ 200, \mathrm{R} \$ 300, \mathrm{R} \$ 400, \mathrm{R} \$ 500, \mathrm{R} \$ 600, \mathrm{R} \$ 700, \mathrm{R} \$ 800 \mathrm{e}$ $\mathrm{R} \$ 1.000$.

(6) Na Tabela 1, a posição na ocupação "outras" inclui funcionários públicos, militares, empregadores, trabalhadores na produção para próprio consumo, na construção para próprio uso, além de trabalhadores não remunerados. 
Elasticidades dos rendimentos do trabalho em relação ao salário mínimo: a experiência de um período recente ...

Gráfico 2

Distribuição percentual das pessoas ocupadas por rendimento do trabalho principal - 2006

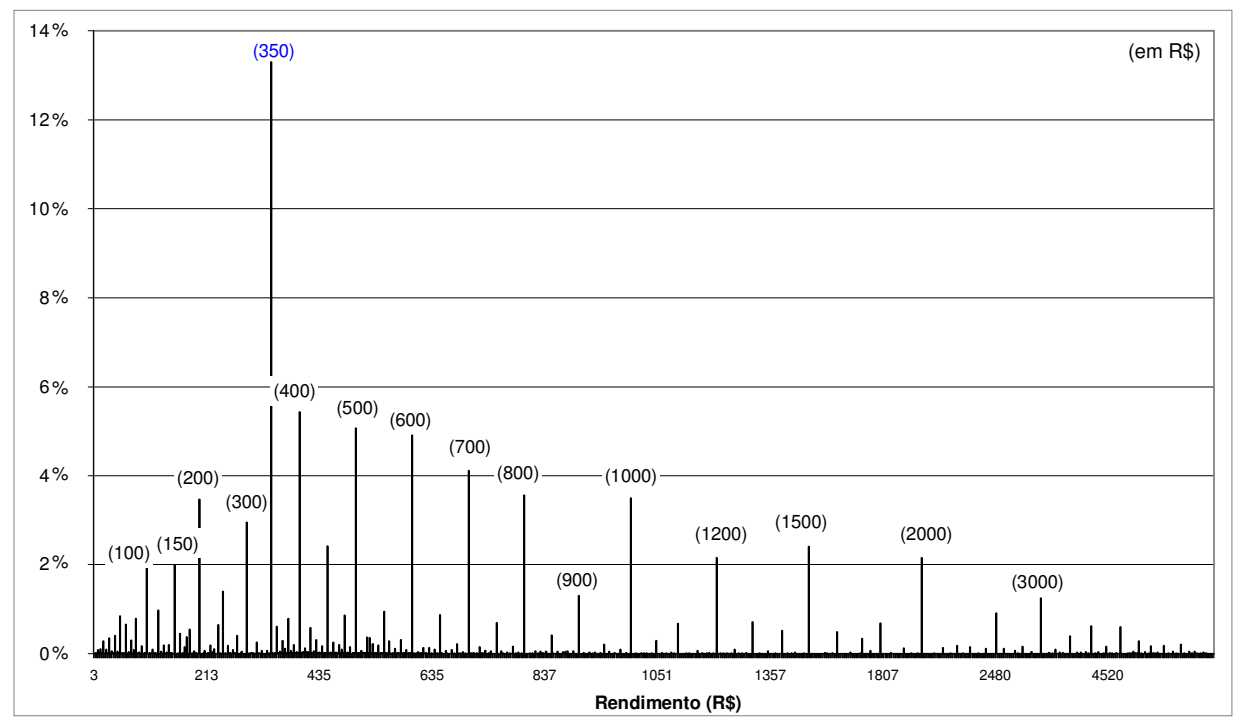

Fonte: PNAD.

Entre 1995 e 2006, a população ocupada no trabalho principal recebendo 1 SM passou de $12,2 \%$ para $13,3 \%$, confirmando que não houve perda de representatividade do SM no período. Houve, entretanto, crescimento da população ocupada recebendo menos de $1 \mathrm{SM}$, que passou de $14,9 \%$ para 22,4\%. Portanto, apesar de manter sua importância como valor utilizado para remunerar os trabalhadores no mercado de trabalho, o grande aumento do SM no período fez com que crescesse a parcela de trabalhadores recebendo valores inferiores ao SM. Os resultados, entretanto, variam bastante dependendo da posição na ocupação considerada (Gráficos 3 a 8).

Quando considerados os trabalhadores mais típicos do setor formal da economia, i.e., os empregados com carteira assinada, verifica-se um aumento substancial daqueles recebendo $1 \mathrm{SM}$, passando de $8,3 \%$ para $14,1 \%$. Na medida em que praticamente não existem pessoas com carteira assinada abaixo do valor do SM, a consequência foi a redução daqueles acima do SM (de 90,1\% para $85,1 \%)$.

O SM é muito importante como referência de remuneração para o emprego doméstico com carteira assinada. De forma até certo ponto surpreendente, a parcela recebendo $1 \mathrm{SM}$ caiu de $38,0 \%$ para $32,8 \%$, ao mesmo tempo em que aumentou a participação daqueles acima de $1 \mathrm{SM}(59,1 \%$ e 65,0\%, respectivamente). Tais dados mostram que os empregados domésticos com 
carteira assinada teriam sido beneficiados com a política de recuperação do SM no período.

Passando-se aos trabalhadores do setor informal, onde os rendimentos são usualmente mais baixos, verifica-se que a tendência geral foi de aumento daqueles abaixo do SM e redução da parcela que recebe $1 \mathrm{SM}$ ou mais. No caso dos empregados sem carteira assinada, o percentual abaixo de 1 SM subiu de 25,8\% para 39,7\% no período. Recebendo exatamente 1 SM, havia 19,9\% em 1995 e 17,2\% em 2006. Portanto, o SM manteve-se como importante referência para os empregados sem carteira assinada, ao mesmo tempo em que houve crescimento daqueles recebendo menos que o mínimo legal.

Para os empregados domésticos sem carteira assinada houve forte queda da parcela que recebe $1 \mathrm{SM}$, passando de $31,0 \%$ para 16,9\%. Em contrapartida, aumentou de $40,0 \%$ para $66,8 \%$ a participação dos trabalhadores domésticos sem carteira recebendo menos que o valor do SM. Tais resultados confirmam os limites da legislação trabalhista para um dos segmentos de trabalhadores informais mais desfavorecidos no país.

Verifica-se, portanto, que tanto para os empregados quanto para os trabalhadores domésticos do setor informal (i.e., sem carteira assinada) o SM possui grande importância como referência salarial, porém com tendência de queda de seu papel no período, ao mesmo tempo em que aumentava bastante o contingente de pessoas recebendo menos de $1 \mathrm{SM}$.

A importância do SM para os trabalhadores por conta própria é bem menor que para os demais aqui analisados. Há relativamente poucos trabalhadores recebendo exatamente $1 \mathrm{SM}$ (6,9\% em 2006), ao mesmo tempo em que aumentava no período a parcela abaixo do SM de $23,8 \%$ para $38,7 \%$. Tal resultado não chega a surpreender, na medida em que os trabalhadores por conta própria são os mais sensíveis às flutuações da conjuntura econômica que apontava para a queda dos rendimentos médios na maior parte do período considerado.

Em resumo, os efeitos do aumento do SM no período 1995/2006 foram bem mais favoráveis para os trabalhadores do setor formal (com carteira) do que do informal (sem carteira e conta própria). Na próxima seção, a análise será aprofundada a partir do cálculo das elasticidades de seus rendimentos em relação ao SM. 
Elasticidades dos rendimentos do trabalho em relação ao salário mínimo: a experiência de um período recente ...

Gráfico 3

Distribuição da população ocupada por rendimento do trabalho principal em relação ao SM $1995 / 2006(\%)$

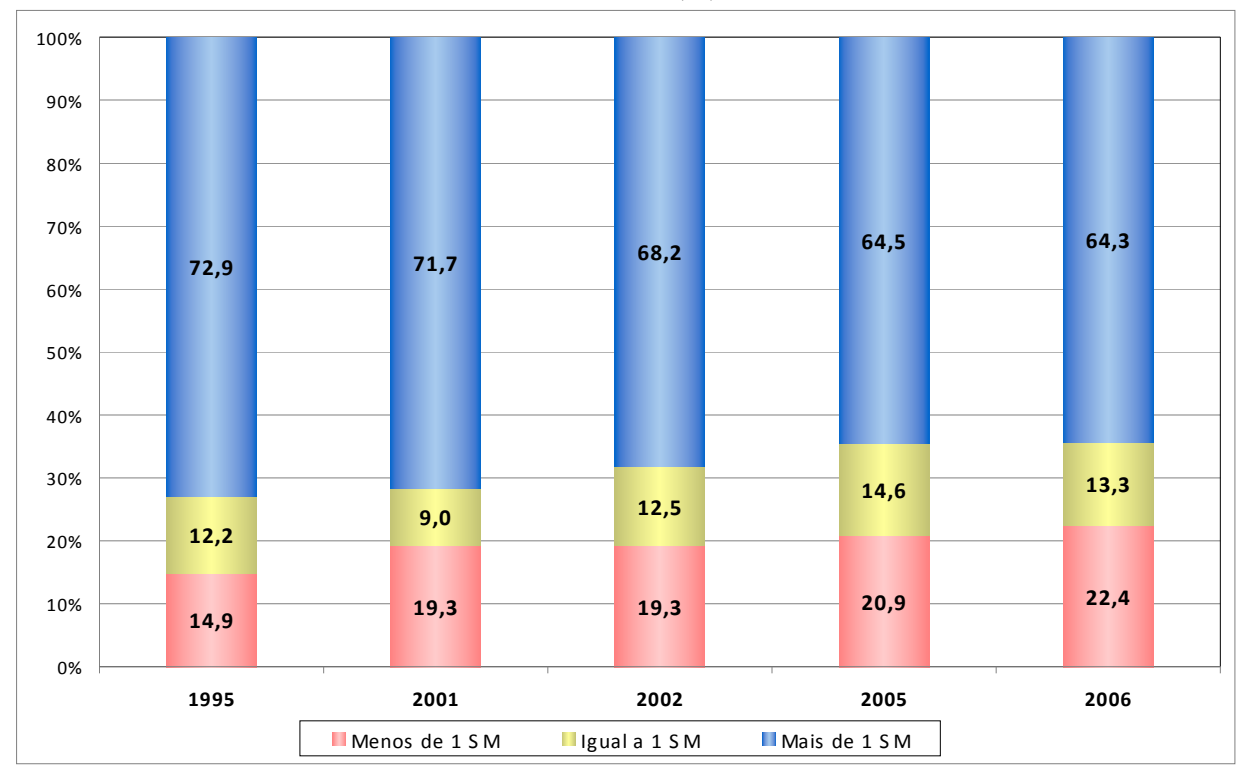

Fonte: PNAD.

Gráfico 4

Distribuição da população ocupada por rendimento do trabalho principal em relação ao SM Empregados com carteira assinada (\%)

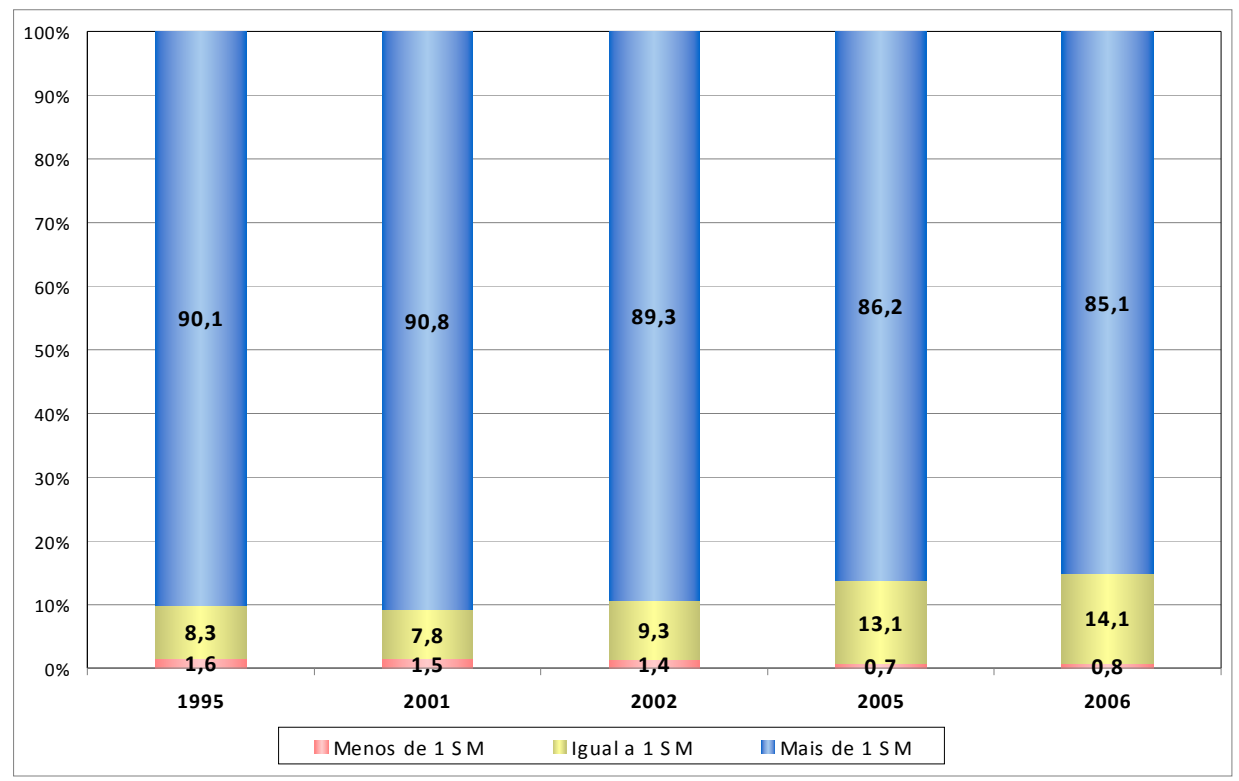

Fonte: PNAD. 


\section{Gráfico 5}

Distribuição da população ocupada por rendimento do trabalho principal em relação ao SM Empregados sem carteira assinada (\%)

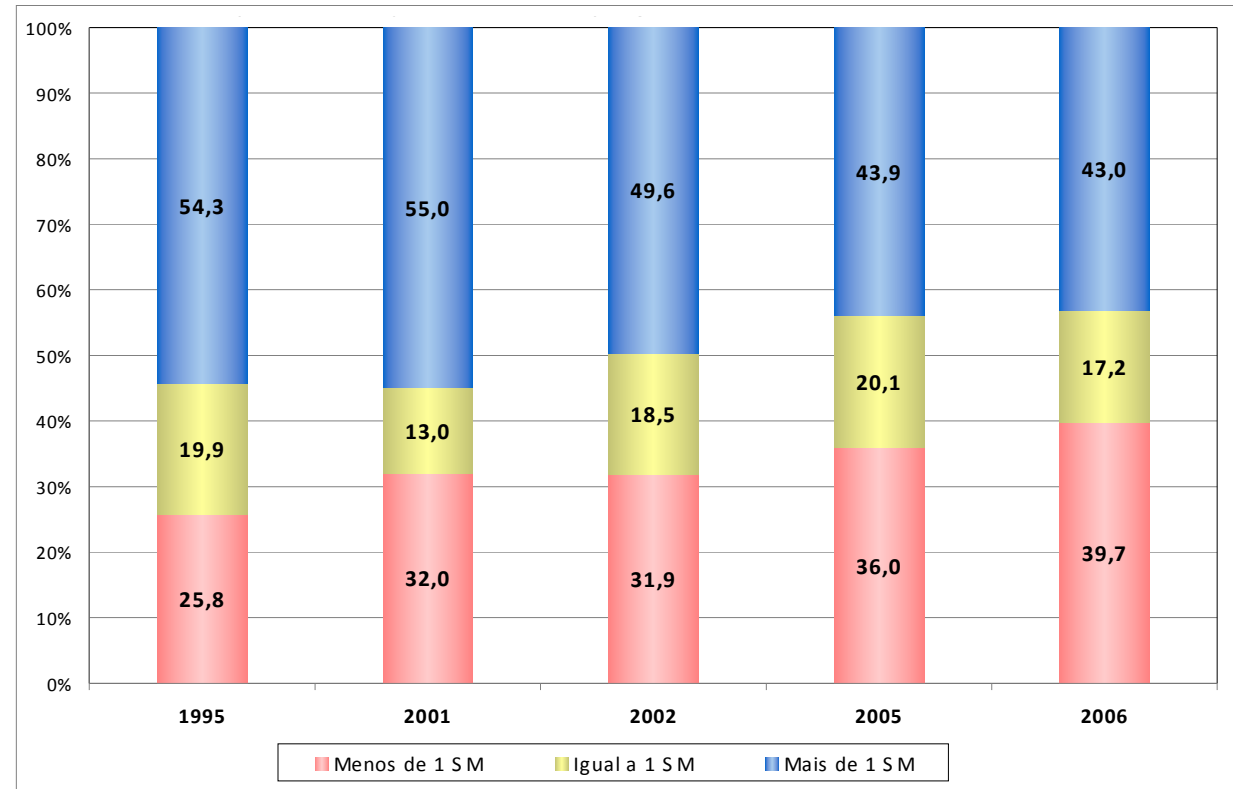

Fonte: PNAD.

Gráfico 6

Distribuição da população ocupada por rendimento do trabalho principal em relação ao SM Trabalhadores por conta própria (\%)

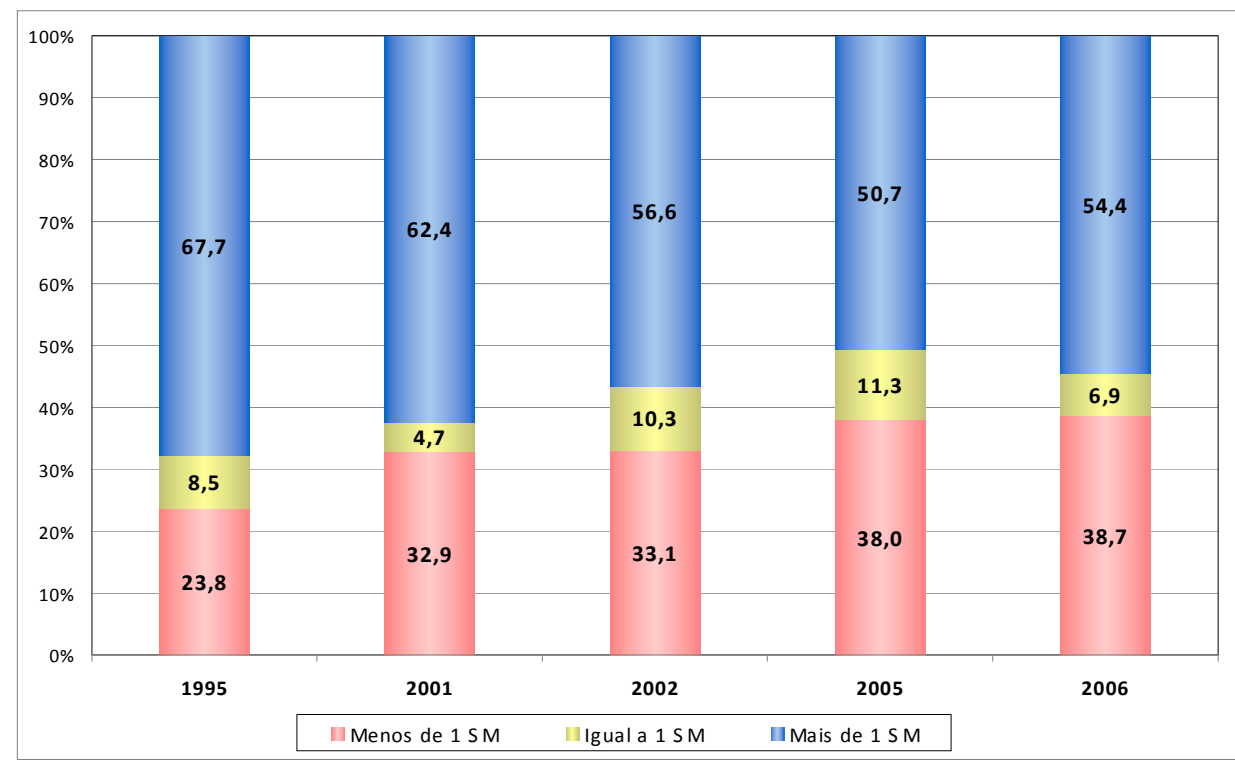

Fonte: PNAD. 
Elasticidades dos rendimentos do trabalho em relação ao salário mínimo: a experiência de um período recente ...

\section{Gráfico 7}

Distribuição da população ocupada por rendimento do trabalho principal em relação ao SM Trabalhadores domésticos com carteira assinada (\%)

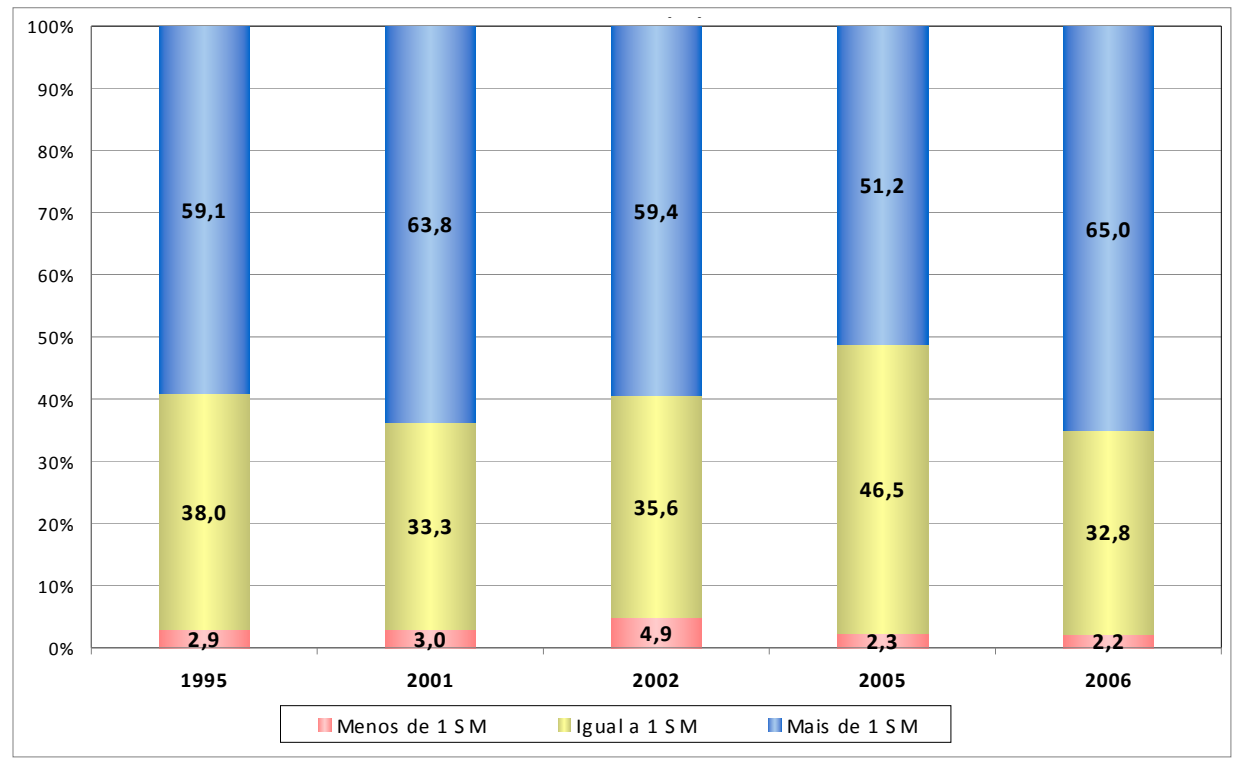

Fonte: PNAD.

Gráfico 8

Distribuição da população ocupada por rendimento do trabalho principal em relação ao SM Trabalhadores domésticos sem carteira assinada (\%)

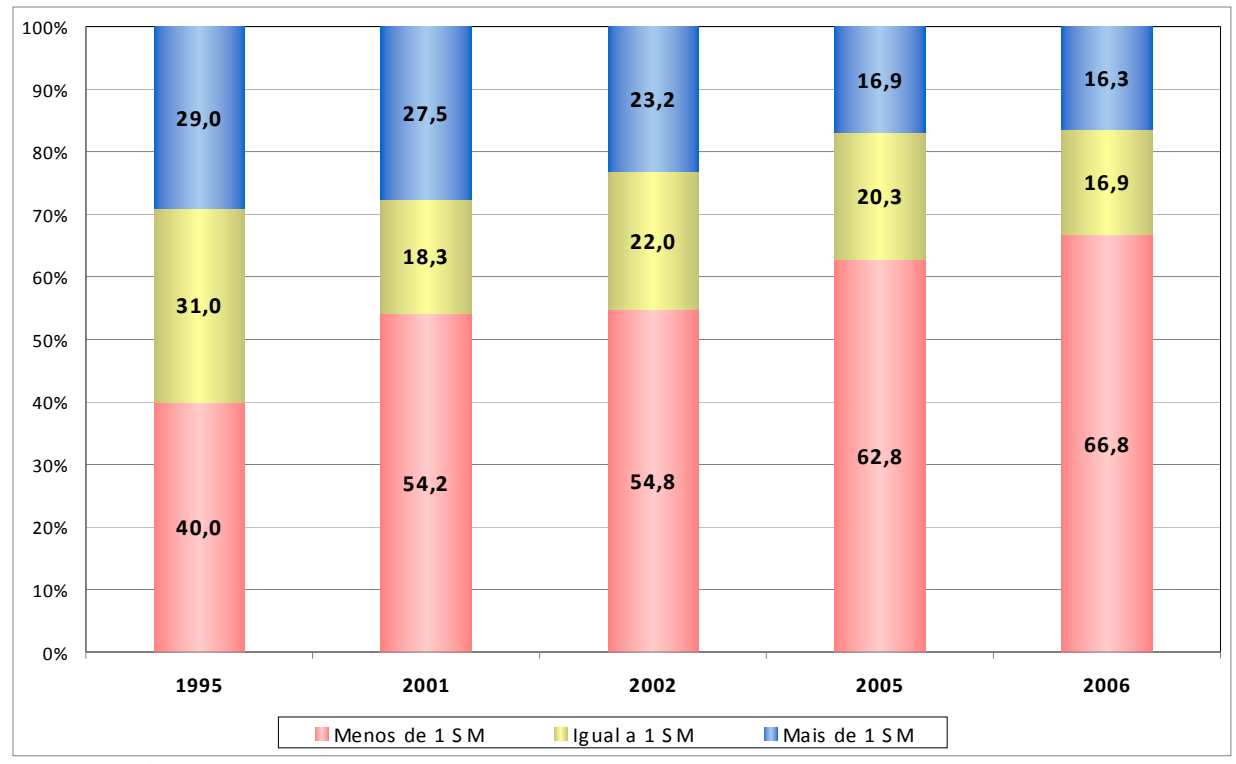

Fonte: PNAD. 
João Saboia

\section{Cálculo das elasticidades}

O cálculo das elasticidades foi realizado separando os rendimentos do trabalho principal em décimos e vigésimos, considerando as mesmas cinco posições da ocupação utilizadas na última seção (empregados com carteira, sem carteira, domésticos com carteira, sem carteira e trabalhadores por conta própria). Além disso, foram considerados seis pares de anos: 1995/2005; 1995/2006; 2001/2005; 2001/2006; 2002/2005; 2002/2006.

Os Gráficos 9 e 10 ilustram as elasticidades calculadas para o rendimento do trabalho principal por décimos e vigésimos da distribuição para os seis períodos selecionados. ${ }^{7}$ Conforme fica bastante nítido, independentemente do período considerado, as elasticidades mais elevadas, com valores próximos da unidade, ocorrem no terceiro décimo e no quinto, sexto e, em alguns anos, sétimo vigésimos da distribuição de rendimentos. Em outras palavras, no entorno do valor do salário mínimo. Na medida em que se consideram níveis superiores ou inferiores de remuneração, as elasticidades diminuem e, dependendo do período, tornam-se até mesmo negativas. Portanto, indiscutivelmente, o salário mínimo é responsável por um comportamento diferenciado e favorável para aqueles com rendimentos do trabalho próximos a seu valor.

Gráfico 9

Elasticidades dos décimos do rendimento do trabalho principal em relação ao SM

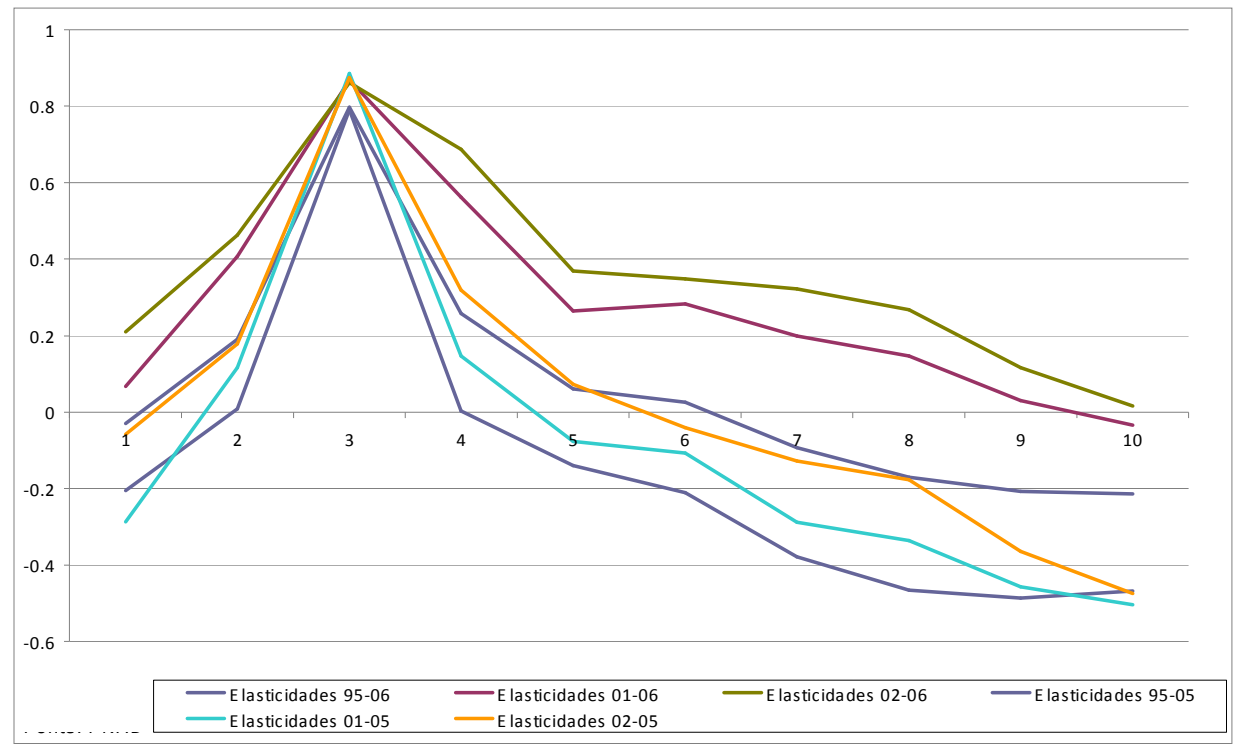

Fonte: PNAD.

(7) Foram também calculadas elasticidades por centésimo da distribuição dos rendimentos do trabalho. Optamos por não utilizar tais elasticidades devido ao fato de que a precisão de tais estimativas é relativamente baixa. Conforme mencionado na seção anterior, os informantes da PNAD tendem a arredondar os dados de rendimentos, distorcendo os cálculos das elasticidades na medida em que são consideradas informações mais desagregadas. 
Elasticidades dos rendimentos do trabalho em relação ao salário mínimo: a experiência de um período recente ...

Gráfico 10

Elasticidades dos vigésimos do rendimento do trabalho principal em relação ao SM

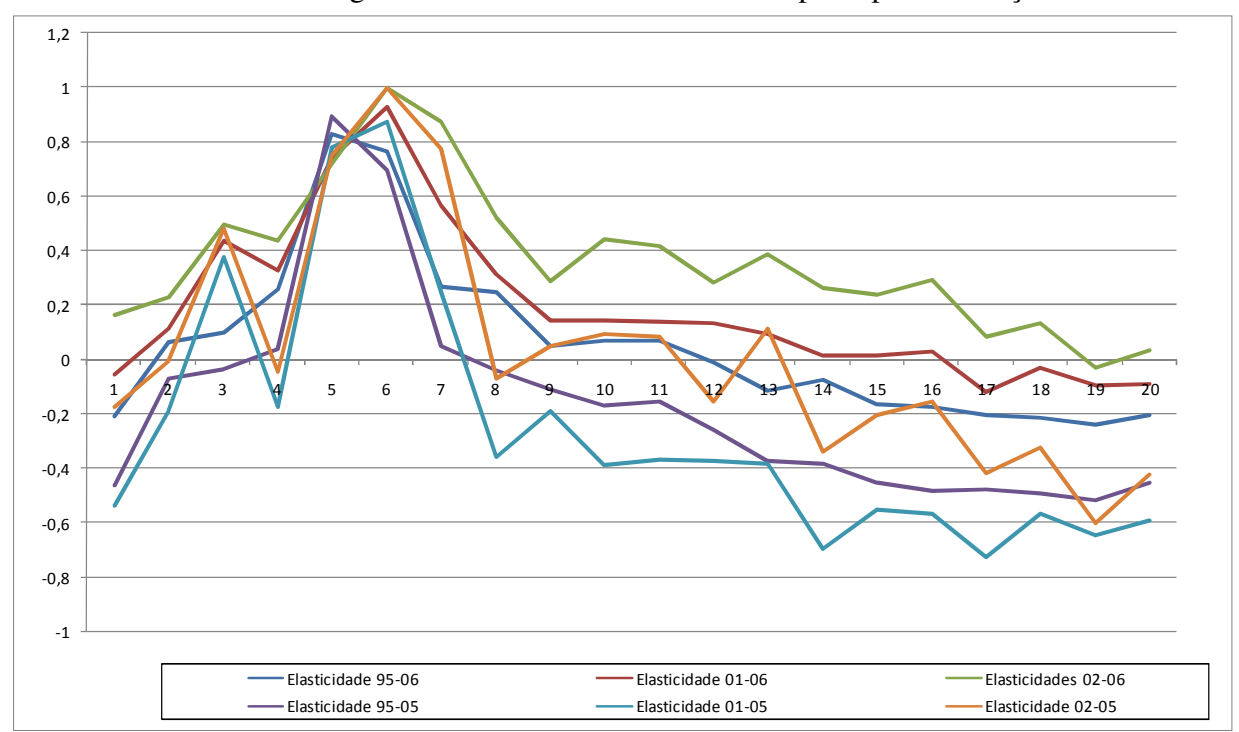

Fonte: PNAD.

Nos períodos mais recentes, especialmente na comparação 2001/2006 e 2002/2006, as elasticidades são mais elevadas, refletindo o próprio crescimento dos rendimentos do trabalho nos últimos anos, que acompanharam mais de perto o aumento do SM. No período 2002/2006, praticamente todas as elasticidades calculadas para os décimos e vigésimos da distribuição são positivas, mantendose, entretanto, mais elevadas nos rendimentos no entorno do valor do SM, com o mesmo formato de um $\mathrm{V}$ invertido assimétrico mais comprido à direita. ${ }^{8}$

Um fato notável que merece ser comentado são os baixíssimos valores das elasticidades para o primeiro décimo (dois primeiros vigésimos) da distribuição do rendimento do trabalho principal, significando que tais níveis de rendimentos do trabalho são tão baixos que estão praticamente descolados do SM.

O comportamento das elasticidades é bastante diferenciado, dependendo da posição na ocupação considerada. Em todos os casos, entretanto, os maiores beneficiados são os trabalhadores nas faixas de remuneração próximas do SM, onde, conforme esperado, as elasticidades são mais elevadas. Os Gráficos 11 a 15 ilustram os resultados para as cinco posições na ocupação analisadas.

No caso dos empregados com carteira assinada, elasticidades próximas à unidade são encontradas no primeiro décimo da distribuição. Para os trabalhadores

(8) Os dados completos para as remunerações e elasticidades nos períodos 1995/2006 e 2002/2006 por décimos da distribuição de rendimentos do trabalho principal estão apresentados no anexo estatístico ao final do artigo. Para facilitar a leitura das tabelas, foram colocados em negrito os valores do SM em 1995, 2002 e 2006 expressos em reais de 2006 corrigidos pelo INPC ( $\mathrm{R} \$ 220, \mathrm{R} \$ 271$ e $\mathrm{R} \$ 350$, respectivamente). 
João Saboia

domésticos com carteira, no segundo, terceiro e quarto décimos. Para os empregados sem carteira, as altas elasticidades correspondem ao quinto décimo. Para os domésticos sem carteira, entre o sétimo e o oitavo décimos.

Até mesmo para os trabalhadores por conta própria, onde a associação dos rendimentos com o salário mínimo é bastante tênue, as elasticidades tendem a ser um pouco mais elevadas no entorno do quinto décimo, onde o nível de rendimento é próximo ao $\mathrm{SM}$.

Analisando mais detalhadamente o caso dos empregados com carteira assinada no período 2002/2006, quando o SM foi beneficiado com um reajuste real da ordem de $33 \%$, verificamos que não apenas os trabalhadores que recebiam $1 \mathrm{SM}$ situados no primeiro décimo foram favorecidos. Aqueles colocados no segundo décimo, por exemplo, tiveram um ganho real de cerca de dois terços do concedido ao SM. Por outro lado, aqueles posicionados do terceiro ao sexto décimos receberam reajustes reais de aproximadamente $40 \%$ daquele dado ao SM. Para os níveis mais elevados de rendimento, a evolução foi bem menos favorável. No último décimo, inclusive, houve queda do rendimento no período (Gráfico 11).

Gráfico 11

Elasticidades dos décimos do rendimento do trabalho principal em relação ao SM

- Empregados com carteira assinada

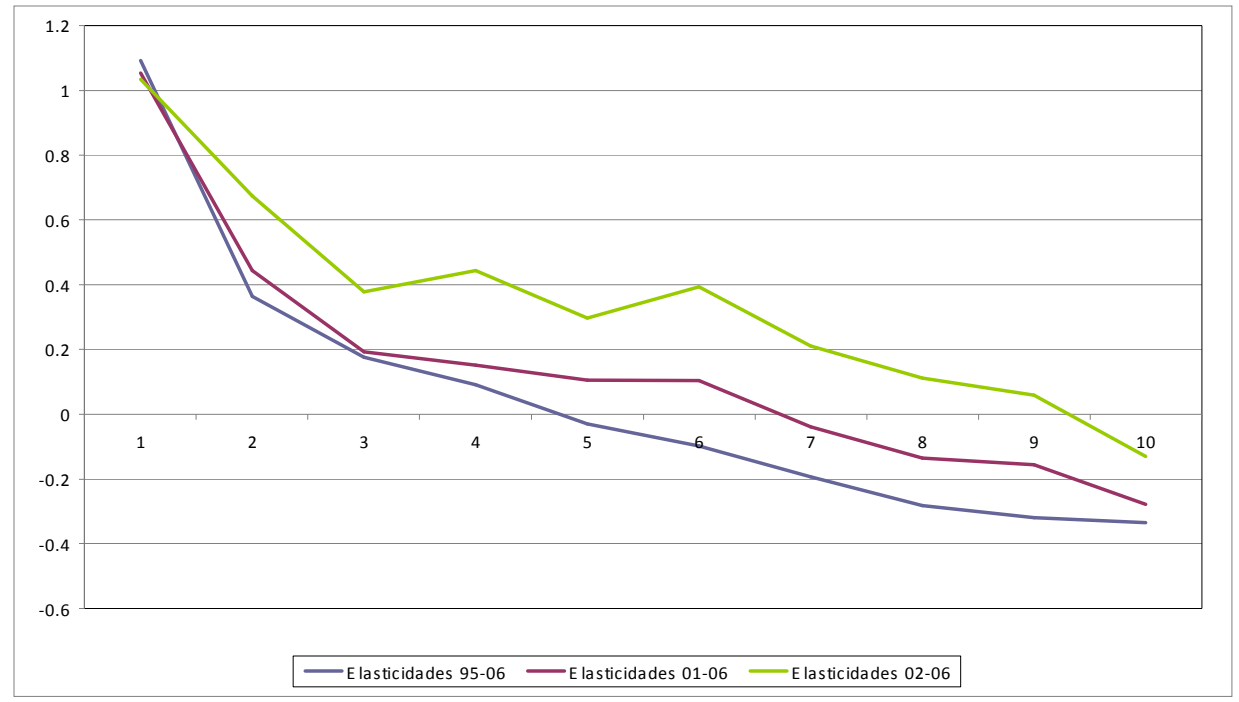

Fonte: PNAD.

Consideremos, em seguida, o caso dos empregados sem carteira assinada. Aqueles situados no quarto décimo da distribuição recebiam 1 SM em 1995. Conforme já apontado na última seção, em 2006, tais trabalhadores recebiam menos do que o novo valor do SM. Apesar disso, 11 anos depois, haviam conquistado cerca de $60 \%$ do ganho real do SM no período. Da mesma forma, os 
Elasticidades dos rendimentos do trabalho em relação ao salário mínimo: a experiência de um período recente ...

empregados sem carteira do quinto décimo recebiam ligeiramente mais que $1 \mathrm{SM}$ em 1995, passando a receber 1 SM em 2006. Isso, entretanto, representou um aumento real correspondente a mais de $80 \%$ do concedido ao SM no mesmo período (elasticidade igual a 0,82 ) (Gráfico 12).

Gráfico 12

Elasticidades dos décimos do rendimento do trabalho principal em relação ao SM

- Empregados sem carteira assinada

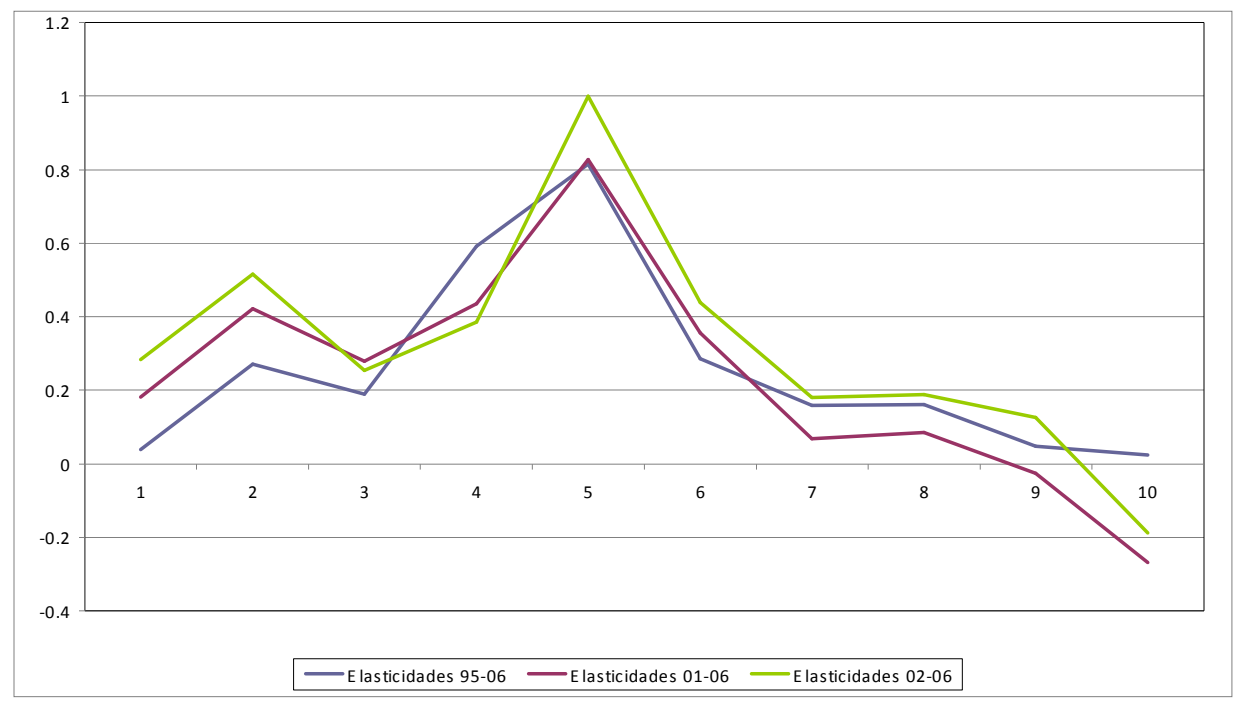

Fonte: PNAD.

Gráfico 13

Elasticidades dos décimos do rendimento do trabalho principal em relação ao SM - Empregados por conta própria

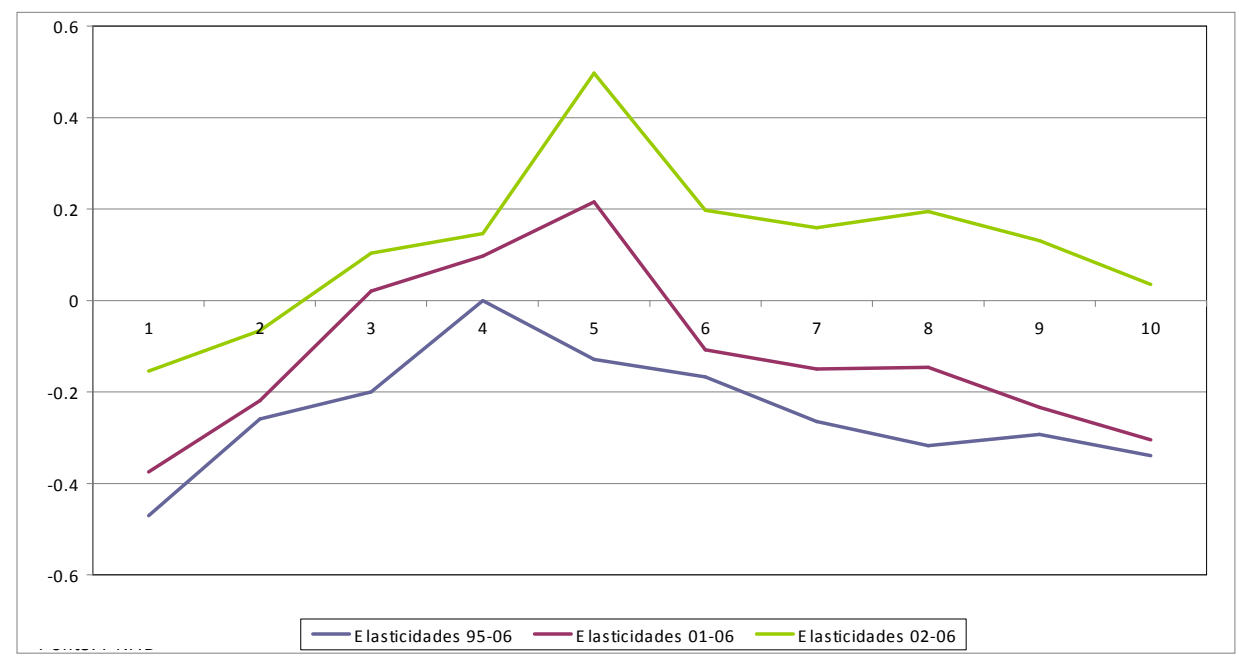

Fonte: PNAD. 
$\mathrm{Na}$ medida em que se consideram níveis de rendimentos mais baixos a situação é bem menos favorável. Apesar disso, mesmo os empregados sem carteira assinada situados no segundo e terceiro décimos da distribuição de rendimentos tiveram crescimento real da ordem de $20 \%$ do concedido ao SM num período em que os rendimentos médios dos trabalhadores caíram. Por sinal, todos os décimos da distribuição dos rendimentos dos empregados sem carteira assinada foram beneficiados com elasticidades positivas no período 1995/2006. Portanto, parcela considerável dos trabalhadores de baixos rendimentos não cobertos pela legislação trabalhista foi beneficiada de alguma forma pelo aumento do SM.

As elasticidades dos trabalhadores domésticos com carteira assinada no período são unitárias até o quarto décimo. A partir daí elas se reduzem monotonicamente. Conforme já mencionado antes, esse foi o contingente de trabalhadores que mais se beneficiou do crescimento do SM ao longo da última década (Gráfico 14).

Gráfico 14

Elasticidades dos décimos do rendimento do trabalho principal em relação ao SM

- Empregados domésticos com carteira assinada

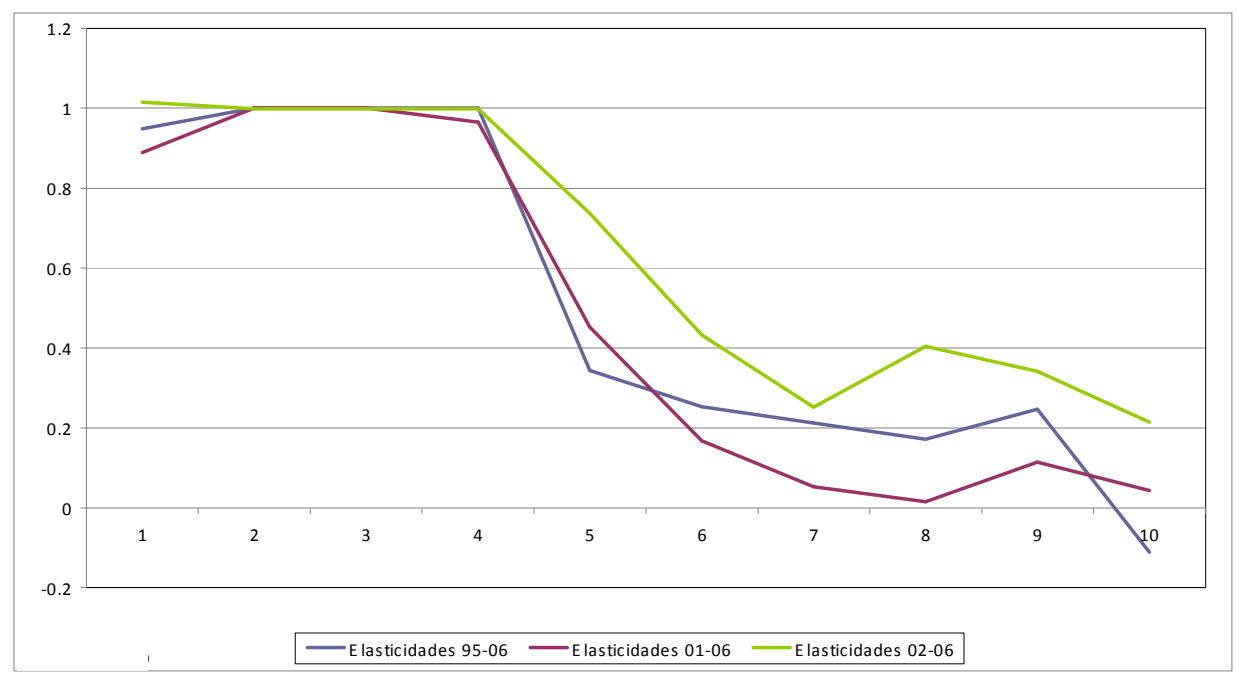

Fonte: PNAD.

A situação mais desfavorável cabe sem dúvida aos trabalhadores domésticos sem carteira assinada que, além de receberem o menor nível de remuneração entre os cinco grupos analisados, sofreram queda em seus rendimentos médios no período 1995/2006. As elasticidades foram positivas apenas do sexto ao oitavo décimos da distribuição de rendimentos, atingindo 0,75 no sétimo décimo, onde o nível de rendimentos correspondia ao valor do SM em 1995 e a pouco menos em 2006 (Gráfico 15). 
Resumindo os principais resultados desta seção, o comportamento das elasticidades mostra que apesar do crescimento da parcela dos trabalhadores recebendo menos que $1 \mathrm{SM}$ no período, houve benefícios para um grande número de pessoas ocupadas nas faixas em torno do valor do SM (acima ou abaixo). Assim, o crescimento do SM no período teria beneficiado tanto aqueles que permaneceram recebendo exatamente $1 \mathrm{SM}$ quanto os demais localizados em valores relativamente próximos, cujas elasticidades foram muito mais elevadas do que para valores distantes do SM, onde a regra geral foi encontrar elasticidades pequenas ou mesmo negativas.

\section{Gráfico 15}

Elasticidades dos décimos do rendimento do trabalho principal em relação ao SM

- Empregados domésticos sem carteira assinada

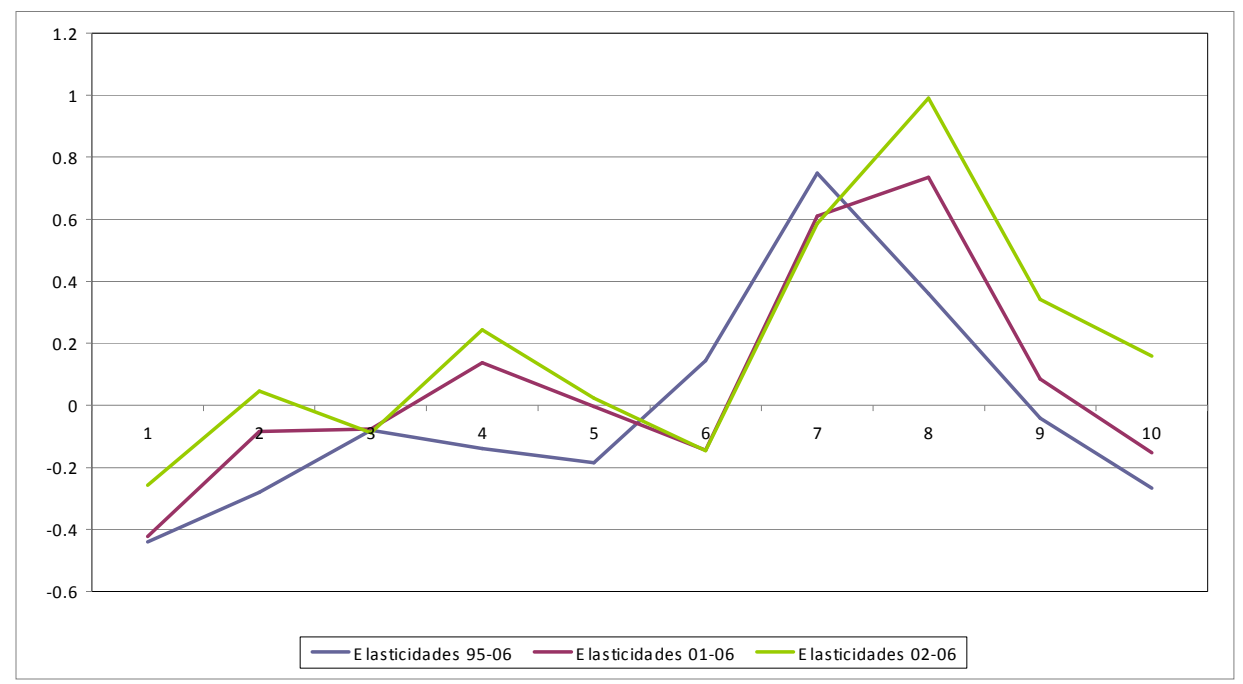

Fonte: PNAD.

\section{Conclusão}

Conforme foi verificado, o SM passou nos últimos anos por um período de forte recuperação de seu valor real. Todavia, ao mesmo tempo em que o SM crescia, houve queda nos rendimentos médios do trabalho, revertida apenas em 2005.

Embora para o conjunto de trabalhadores analisados não tenha havido queda da parcela que recebe exatamente $1 \mathrm{SM}$, foi identificado um crescimento da parcela abaixo do nível mínimo legal de remuneração, tendo sido levantadas dúvidas, no início do artigo, sobre os reais benefícios do crescimento do SM para o conjunto de trabalhadores. 
A situação é bastante diferenciada dependendo da posição na ocupação considerada. Em geral, os trabalhadores do setor formal (com carteira assinada) foram os que mais se beneficiaram, na medida em que o SM é usualmente a remuneração mínima utilizada. No caso do setor informal (sem carteira assinada e conta própria), entretanto, houve nítido crescimento daqueles recebendo menos de $1 \mathrm{SM}$, ao mesmo tempo em que a tendência foi de queda dos que recebiam $1 \mathrm{SM}$.

O cálculo das elasticidades da remuneração do trabalho em relação ao salário mínimo deixa claro que os trabalhadores com rendimentos no entorno do valor do SM também foram beneficiados pelo aumento do SM, tanto no setor formal quanto no informal. Suas elasticidades são sistematicamente superiores às encontradas para os demais trabalhadores, recebam eles altas remunerações ou níveis extremamente baixos, onde o papel do SM é mínimo.

Os resultados encontrados neste artigo apontam em direção à importância do SM para a melhoria da distribuição dos rendimentos do trabalho. Se num período em que a economia cresceu pouco e em que os rendimentos médios do trabalho caíram foi possível aumentar consideravelmente os rendimentos de uma grande parcela de trabalhadores nas faixas próximas ao SM, certamente a situação teria sido ainda mais positiva se a economia estivesse crescendo a taxas elevadas.

Nos últimos anos, a conjuntura política foi favorável aos reajustes relativamente generosos recebidos pelo SM. É importante a existência de uma regra clara para os reajustes, que transfira automaticamente para o SM uma parcela do crescimento econômico e do aumento da produtividade. Isso reduz bastante o grau de incerteza que atingia a economia no passado em períodos próximos aos reajustes do SM.

Conforme já salientado, os trabalhadores na extremidade inferior da pirâmide de rendimentos do setor informal são muito pouco afetados pela política do SM. Para eles, a melhoria dos rendimentos do trabalho deve necessariamente ser complementada com medidas na área de assistência social, portanto, fora do mercado de trabalho.

Em resumo, os resultados aqui obtidos corroboram aqueles encontrados por outros autores, mostrando que, no passado recente, quando o SM teve um crescimento acelerado, houve repasse de seu aumento para as faixas de remuneração próximas, nitidamente beneficiadas quando comparadas com aquelas nos extremos superiores e inferiores da distribuição de rendimentos do trabalho.

\section{Bibliografia}

BALTAR, P.; DEDECCA, C.; KREIN, J. (Org.). Salário mínimo e desenvolvimento. Campinas: Unicamp, 2005. 
BARROS, R.; CORSEUIL, C.; CURY, S. Salário mínimo e pobreza no Brasil: estimativas que consideram efeitos de equilíbrio geral. Pesquisa e Planejamento Econômico, v. 30, n. 2, 2000.

CORSEUIL, C.; SERVO, L. Salário mínimo e bem-estar social no Brasil. Uma resenha da literatura. Rio de Janeiro: Ipea, 2002. (Texto para Discussão, n. 880).

FAJNZYLBER, P. Minimum wage effects through the wage distribution: evidence from Brazil's formal and informal sectors. Belo Horizonte: Cedeplar/UFMG, 2001. (Texto para Discussão, n. 151).

FOGUEL, M.; RAMOS, L.; CARNEIRO, F. The impact of minimum wage on the labor market, poverty and fiscal budget in Brazil. Rio de Janeiro: Ipea, 2001. (Texto para Discussão, n. 839).

GIAMBIAGI, F.; FRANCO, S. Esgotamento do papel do salário mínimo como mecanismo de combate à pobreza extrema. Rio de Janeiro: Ipea, 2007. (Texto para Discussão, n. 1290).

LEMOS, S. The effects of minimum wage on wages and employment in Brazil - A menu of minimum wage variables. University College of London, 2001. Mimeografado.

Minimum wage effects on wages, employment and prices: implications for poverty alleviation in Brazil. University of Leicester, 2005. (Working Paper, 05/15).

NERI, M.; GONZAGA, G.; CAMARGO, J. Salário mínimo, efeito farol e pobreza. Revista de Economia Política, v. 21, n. 2, 2001.

SABOIA, J. Efeitos do salário mínimo sobre a distribuição de renda no Brasil no período 1995/2005 - Resultados de simulações. Econômica, v. 9, n. 2, 2007.

SOARES, S. O impacto distributivo do salário mínimo: a distribuição individual dos rendimentos do trabalho. Rio de Janeiro: Ipea, 2002. (Texto para Discussão, n. 873).

Análise do bem-estar e decomposição por fatores da queda na desigualdade entre 1995 e 2004. Econômica, v. 8, n. 1, 2006.

ULYSSEA, G.; FOGUEL, M. Efeitos do salário mínimo sobre o mercado de trabalho brasileiro. Rio de Janeiro: Ipea, 2006. (Texto para Discussão, n. 1168). 
João Saboia

\section{Anexo Estatístico}

Variação real e elasticidades por décimos da distribuição dos rendimentos do trabalho principal - 1995/2006 e 2002/2006

Tabela A1

Elasticidades - 1995/2006

\begin{tabular}{c|c|c|c|c|c|c}
\hline Décimos & Trab. Princ. & C/Carteira & S/Carteira & Conta própria & Dom.C/Cart. & Dom.S/Cart. \\
\hline 1 & $-0,03$ & 1,09 & 0,04 & $-0,47$ & 0,95 & $-0,44$ \\
\hline 2 & 0,19 & 0,36 & 0,27 & $-0,26$ & 1,00 & $-0,28$ \\
\hline 3 & 0,80 & 0,18 & 0,19 & $-0,20$ & 1,00 & $-0,08$ \\
\hline 4 & 0,26 & 0,09 & 0,59 & 0,00 & 1,00 & $-0,14$ \\
\hline 5 & 0,06 & $-0,03$ & 0,82 & $-0,13$ & 0,34 & $-0,19$ \\
\hline 6 & 0,03 & $-0,10$ & 0,29 & $-0,17$ & 0,25 & 0,14 \\
\hline 7 & $-0,09$ & $-0,19$ & 0,16 & $-0,26$ & 0,21 & 0,75 \\
\hline 8 & $-0,17$ & $-0,28$ & 0,16 & $-0,32$ & 0,17 & 0,36 \\
\hline 9 & $-0,21$ & $-0,32$ & 0,05 & $-0,29$ & 0,25 & $-0,04$ \\
\hline 10 & $-0,21$ & $-0,33$ & 0,02 & $-0,34$ & $-0,11$ & $-0,27$ \\
\hline Total & $-0,12$ & $-0,19$ & 0,15 & $-0,29$ & 0,33 & $-0,02$ \\
\hline
\end{tabular}

Fonte: PNAD.

Tabela A2

Trab. Principal

\begin{tabular}{c|r|r|r}
\hline Décimos & 1995 & 2006 & Variação \\
\hline 1 & 91 & 89 & $-0,02$ \\
\hline 2 & 198 & 220 & 0,11 \\
\hline 3 & 231 & 339 & 0,47 \\
\hline 4 & 317 & 365 & 0,15 \\
\hline 5 & 417 & 432 & 0,04 \\
\hline 6 & 522 & 530 & 0,01 \\
\hline 7 & 692 & 655 & $-0,05$ \\
\hline 8 & 963 & 867 & $-0,10$ \\
\hline 9 & 1486 & 1304 & $-0,12$ \\
\hline 10 & 4259 & 3725 & $-0,13$ \\
\hline Total & 918 & 853 & $-0,07$ \\
\hline Fon
\end{tabular}

Fonte: PNAD.
Tabela A3

Trab. Principal - Empr. c/ Carteira

\begin{tabular}{c|r|r|r}
\hline Décimos & 1995 & 2006 & Variação \\
\hline 1 & 207 & 340 & 0,64 \\
\hline 2 & 302 & 366 & 0,21 \\
\hline 3 & 380 & 420 & 0,10 \\
\hline 4 & 460 & 485 & 0,05 \\
\hline 5 & 565 & 555 & $-0,02$ \\
\hline 6 & 677 & 638 & $-0,06$ \\
\hline 7 & 839 & 744 & $-0,11$ \\
\hline 8 & 1095 & 913 & $-0,17$ \\
\hline 9 & 1580 & 1284 & $-0,19$ \\
\hline 10 & 4011 & 3221 & $-0,20$ \\
\hline Total & 1012 & 897 & $-0,11$ \\
\hline
\end{tabular}

Fonte: PNAD. 
Elasticidades dos rendimentos do trabalho em relação ao salário mínimo: a experiência de um período recente ...

Tabela A4

Trab. Principal - Empr. s/ Carteira

\begin{tabular}{c|r|r|r}
\hline Décimos & 1995 & 2006 & Variação \\
\hline 1 & 77 & 79 & 0,02 \\
\hline 2 & 141 & 164 & 0,16 \\
\hline 3 & 200 & 222 & 0,11 \\
\hline 4 & 220 & 297 & 0,35 \\
\hline 5 & 237 & 350 & 0,48 \\
\hline 6 & 306 & 357 & 0,17 \\
\hline 7 & 378 & 413 & 0,09 \\
\hline 8 & 474 & 519 & 0,09 \\
\hline 9 & 688 & 707 & 0,03 \\
\hline 10 & 1909 & 1935 & 0,01 \\
\hline Total & 463 & 504 & 0,09 \\
\hline
\end{tabular}

Fonte: PNAD.

Tabela A6

Trab. Principal - Domésticos c/ Carteira

\begin{tabular}{c|r|r|r}
\hline Décimos & 1995 & 2006 & Variação \\
\hline 1 & 198 & 308 & 0,56 \\
\hline 2 & 220 & 350 & 0,59 \\
\hline 3 & 220 & 350 & 0,59 \\
\hline 4 & 220 & 350 & 0,59 \\
\hline 5 & 291 & 350 & 0,20 \\
\hline 6 & 331 & 380 & 0,15 \\
\hline 7 & 375 & 422 & 0,12 \\
\hline 8 & 441 & 485 & 0,10 \\
\hline 9 & 509 & 582 & 0,15 \\
\hline 10 & 896 & 838 & $-0,07$ \\
\hline Total & 370 & 442 & 0,19 \\
\hline
\end{tabular}

Fonte: PNAD.
Tabela A5

Trab. Principal - Conta própria

\begin{tabular}{c|r|r|r}
\hline Décimos & 1995 & 2006 & Variação \\
\hline 1 & 60 & 43 & $-0,28$ \\
\hline 2 & 131 & 111 & $-0,15$ \\
\hline 3 & 207 & 182 & $-0,12$ \\
\hline 4 & 270 & 270 & 0,00 \\
\hline 5 & 374 & 346 & $-0,08$ \\
\hline 6 & 474 & 428 & $-0,10$ \\
\hline 7 & 654 & 552 & $-0,16$ \\
\hline 8 & 925 & 752 & $-0,19$ \\
\hline 9 & 1358 & 1124 & $-0,17$ \\
\hline 10 & 3654 & 2924 & $-0,20$ \\
\hline Total & 811 & 673 & $-0,17$ \\
\hline
\end{tabular}

Fonte: PNAD.

Tabela A7

Trab. Principal - Domésticos s/ Carteira

\begin{tabular}{|c|c|c|c|}
\hline Décimos & 1995 & 2006 & Variação \\
\hline 1 & 64 & 48 & $-0,26$ \\
\hline 2 & 108 & 90 & $-0,16$ \\
\hline 3 & 129 & 123 & $-0,05$ \\
\hline 4 & 173 & 159 & $-0,08$ \\
\hline 5 & 220 & 196 & $-0,11$ \\
\hline 6 & 220 & 239 & 0,08 \\
\hline 7 & 220 & 317 & 0,44 \\
\hline 8 & 289 & 350 & 0,21 \\
\hline 9 & 389 & 379 & $-0,02$ \\
\hline 10 & 713 & 601 & $-0,16$ \\
\hline Total & 253 & 250 & $-0,01$ \\
\hline
\end{tabular}

Fonte: PNAD.

Tabela A8

Elasticidades - 2002/2006

\begin{tabular}{c|c|c|c|c|c|c}
\hline Décimos & Trab. Princ. & C/Carteira & S/Carteira & Conta própria & Dom. C/Cart. & Dom.S/Cart. \\
\hline 1 & 0,21 & 1,03 & 0,28 & $-0,15$ & 1,02 & $-0,26$ \\
\hline 2 & 0,46 & 0,67 & 0,52 & $-0,07$ & 1,00 & 0,05 \\
\hline 3 & 0,86 & 0,38 & 0,25 & 0,10 & 1,00 & $-0,09$ \\
\hline 4 & 0,69 & 0,44 & 0,39 & 0,15 & 1,00 & 0,24 \\
\hline 5 & 0,37 & 0,30 & 1,00 & 0,50 & 0,74 & 0,02 \\
\hline 6 & 0,35 & 0,39 & 0,44 & 0,20 & 0,43 & $-0,15$ \\
\hline 7 & 0,32 & 0,21 & 0,18 & 0,16 & 0,25 & 0,59 \\
\hline 8 & 0,27 & 0,11 & 0,19 & 0,19 & 0,40 & 0,99 \\
\hline 9 & 0,12 & 0,06 & 0,13 & 0,13 & 0,34 & 0,34 \\
\hline 10 & 0,02 & $-0,13$ & $-0,19$ & 0,04 & 0,21 & 0,16 \\
\hline Total & 0,10 & $-0,03$ & 0,08 & $-0,02$ & 0,39 & 0,16 \\
\hline Fonte: PNAD & & & & & &
\end{tabular}


Tabela A9

Trab. Principal

\begin{tabular}{c|r|r|c}
\hline Décimos & 2002 & 2006 & Variação \\
\hline 1 & 84 & 89 & 0,06 \\
\hline 2 & 194 & 220 & 0,14 \\
\hline 3 & 271 & 339 & 0,25 \\
\hline 4 & 304 & 365 & 0,20 \\
\hline 5 & 389 & 432 & 0,11 \\
\hline 6 & 481 & 530 & 0,10 \\
\hline 7 & 598 & 655 & 0,09 \\
\hline 8 & 804 & 867 & 0,08 \\
\hline 9 & 1261 & 1304 & 0,03 \\
\hline 10 & 3707 & 3725 & 0,00 \\
\hline Total & 827 & 853 & 0,03 \\
\hline
\end{tabular}

Fonte: PNAD.

Tabela A11

Trab. Principal - Empr. s/ Carteira

\begin{tabular}{c|r|r|r}
\hline Décimos & 2002 & 2006 & Variação \\
\hline 1 & 73 & 79 & 0,08 \\
\hline 2 & 142 & 164 & 0,15 \\
\hline 3 & 206 & 222 & 0,07 \\
\hline 4 & 267 & 297 & 0,11 \\
\hline 5 & 271 & 350 & 0,29 \\
\hline 6 & 317 & 357 & 0,13 \\
\hline 7 & 392 & 413 & 0,05 \\
\hline 8 & 492 & 519 & 0,06 \\
\hline 9 & 682 & 707 & 0,04 \\
\hline 10 & 2049 & 1935 & $-0,06$ \\
\hline Total & 493 & 504 & 0,02 \\
\hline
\end{tabular}

Fonte: PNAD.

Tabela A13

Trab. Principal - Domésticos c/ Carteira

\begin{tabular}{c|c|c|c}
\hline Décimos & 2002 & 2006 & Variação \\
\hline 1 & 237 & 308 & 0,30 \\
\hline 2 & 271 & 350 & 0,29 \\
\hline 3 & 271 & 350 & 0,29 \\
\hline 4 & 271 & 350 & 0,29 \\
\hline 5 & 288 & 350 & 0,22 \\
\hline 6 & 337 & 380 & 0,13 \\
\hline 7 & 393 & 422 & 0,07 \\
\hline 8 & 434 & 485 & 0,12 \\
\hline 9 & 529 & 582 & 0,10 \\
\hline 10 & 788 & 838 & 0,06 \\
\hline Total & 396 & 442 & 0,11 \\
\hline Fon
\end{tabular}

Fonte: PNAD.
Tabela A10

Trab. Principal - Empr. c/ Carteira

\begin{tabular}{c|r|r|r}
\hline Décimos & 2002 & 2006 & Variação \\
\hline 1 & 261 & 340 & 0,30 \\
\hline 2 & 306 & 366 & 0,20 \\
\hline 3 & 378 & 420 & 0,11 \\
\hline 4 & 429 & 485 & 0,13 \\
\hline 5 & 510 & 555 & 0,09 \\
\hline 6 & 572 & 638 & 0,12 \\
\hline 7 & 700 & 744 & 0,06 \\
\hline 8 & 884 & 913 & 0,03 \\
\hline 9 & 1263 & 1284 & 0,02 \\
\hline 10 & 3348 & 3221 & $-0,04$ \\
\hline Total & 905 & 897 & $-0,01$ \\
\hline
\end{tabular}

Fonte: PNAD.

Tabela A12

Trab. Principal - Conta própria

\begin{tabular}{c|r|r|r}
\hline Décimos & 2002 & 2006 & Variação \\
\hline 1 & 46 & 43 & $-0,05$ \\
\hline 2 & 113 & 111 & $-0,02$ \\
\hline 3 & 177 & 182 & 0,03 \\
\hline 4 & 259 & 270 & 0,04 \\
\hline 5 & 302 & 346 & 0,15 \\
\hline 6 & 404 & 428 & 0,06 \\
\hline 7 & 527 & 552 & 0,05 \\
\hline 8 & 712 & 752 & 0,06 \\
\hline 9 & 1083 & 1124 & 0,04 \\
\hline 10 & 2895 & 2924 & 0,01 \\
\hline Total & 677 & 673 & $-0,01$ \\
\hline
\end{tabular}

Fonte: PNAD.

Tabela A14

Trab. Principal - Domésticos s/ Carteira

\begin{tabular}{c|r|r|r}
\hline Décimos & 2002 & 2006 & Variação \\
\hline 1 & 51 & 48 & $-0,08$ \\
\hline 2 & 89 & 90 & 0,01 \\
\hline 3 & 126 & 123 & $-0,03$ \\
\hline 4 & 148 & 159 & 0,07 \\
\hline 5 & 195 & 196 & 0,01 \\
\hline 6 & 250 & 239 & $-0,04$ \\
\hline 7 & 271 & 317 & 0,17 \\
\hline 8 & 271 & 350 & 0,29 \\
\hline 9 & 344 & 379 & 0,10 \\
\hline 10 & 574 & 601 & 0,05 \\
\hline Total & 239 & 250 & 0,05 \\
\hline
\end{tabular}

Fonte: PNAD. 